\title{
Peroxisome Biogenesis Disorder 2B
}

National Cancer Institute

\section{Source}

National Cancer Institute. Peroxisome Biogenesis Disorder 2B. NCI Thesaurus. Code C155751.

An autosomal recessive condition caused by mutation(s) in the PEX5 gene, encoding peroxisomal targeting signal 1 receptor. Peroxisome biogenesis disorder $2 \mathrm{~B}$ is characterized by overlapping phenotypes of neonatal adrenoleukodystrophy and infantile Refsum disease. 